\title{
Performance Analysis of Reverse Supply Chain Systems by Using Simulation
}

\author{
Shigeki Umeda \\ Musashi University, \\ 1-26 Toyotama-kami Nerima Tokyo 176-8534, Japan \\ shigeki@cc.musashi.ac.jp
}

\begin{abstract}
This paper proposes methodologies of simulation modeling and analysis of supply chain systems with reverse logistics flows. This paper discusses two types of reverse supply chain: PUSH-type reverse logistics and PULL-type reverse logistics. Generic models are introduced and analysis examples of individual features will be provided.
\end{abstract}

Keywords: Reverse supply chain, Simulation, Performance evaluation, Reverse logistics.

\section{$1 \quad$ Introduction}

A supply chain system is a chain of processes from the initial raw materials to the ultimate consumption of the finished product spanning across multiple suppliercustomer links. It provides functions within and outside a company that enable the value chain to make products and provide services to the customers. There are many discussions on supply chain operations.

In the last decade, due to environmental and ecological responsibility, enterprises are trying to reuse, remanufacture and recycle the used products to reduce the negative impact on environment, especially the manufacturers of the electrical consumer products. Requirements for corporate responsibility and sustainability are getting more urgent.

Reverse supply chain problems have been discussed from various viewpoints. Gupta at al. reviewed sustainable supply chain systems from management view [1]. Chouinarda at al. discussed reverse logistics activities, and proposed information support system, which covers recovery, processing of unused products, and redistribution of reusable materials [2]. Chung and Wee developed an integrated deteriorating inventory model with green-component lifecycle value design and remanufacturing [3]. Fuente et al. proposed an integrated model for the forward and reverse supply chain management (IMSCM) and demonstrated an application to a metal-mechanic company. This model covers demand management, order management, manufacturing management Procedures, Procurement Management Procedures, Distribution Management Procedures, Client Management Procedures, etc.[4]. Emilianni discussed the use of online reverse auctions to source engineered components in global aerospace supply chains using online reverse auctions [5]. Gou et al. discussed an optimal delivery policy of delivery and showed the formulas for optimal policies of 
delivery by using modifications of the EOQ model [6]. Minner combined the problem of safety stock planning in a general supply chain with the integration of external and internal product return and reuse [7]. Nagumey and Toyasaki developed an integrated framework for the modeling of reverse supply chain management of electronic waste, which includes recycling [8]. They described the behavior of the various decisionmakers, and constructed the multitiered e-cycling network equilibrium models.

Performance analysis of supply chain systems is a critical issue in its design stage. Simulation is such a generic approach that gives solutions of performance analysis of supply chain systems. Chan et al. applied simulation to analysis of impact of collaborative transportations in supply chain systems [9]. Chatfield et al. developed a supply chain simulation system by using an object-oriented modeling method [10]. Labarthe et al. proposed an agent-based modeling and simulation of supply chain systems [11]. Umeda and Lee developed a general purpose supply chain simulator [12].

This paper proposes methodologies of simulation modeling and analysis of supply chain systems with reverse logistics flows, and discusses system performance of two types of reverse supply chains: PUSH-type reverse model and PULL-type reverse model. The characteristics of each model will be analyzed by using discrete-event simulation. Section 2 describes scenarios and models for the reverse supply chain system. Section 3 represents simulation-based performances evaluations. And, the final section summarizes the characteristics in each model.

\section{Models of Reverse Logistics Supply Chains}

\subsection{Reverse Logistics Scenarios}

Reverse logistics systems require taking back products from customers and the repairing, remanufacturing (value-added recovery), or recycling (material recovery) the returned products. The reverse logistics in supply chains is strongly related to all stages of a product development and is also a critical problem to all level of the industry.

There are many types of reverse logistics [1]. We, here, consider a virtual supply chain system, which is composed of the following components: Chain manager, Supplier, Manufacturer, Retailer, Customers, Collector, and Remanufacturer (Fig.1). This model supposes home electric appliances such as PCs, TVs, and refrigerators

Chain manager receives demand order from Customer. The manager predicts demand in next ordering duration by using Customer's order. The manager also gives production orders production orders to Manufacturer and Supplier by using the predicted demands. Customer uses products, and sends the used products to Collector.

Supplier, Manufacturer, and Retailer are members that form arterial flows (production generation flows) in a chain. Supplier provides parts or materials to Manufacturer according as supply orders from Chain manager. Manufacturer provides products to Retailer according as production orders from Chain manager. Retailer provides products to Customer according as Demand (Purchase) order from Customer. These chain members use Deliverers to carry materials to its downstream. 


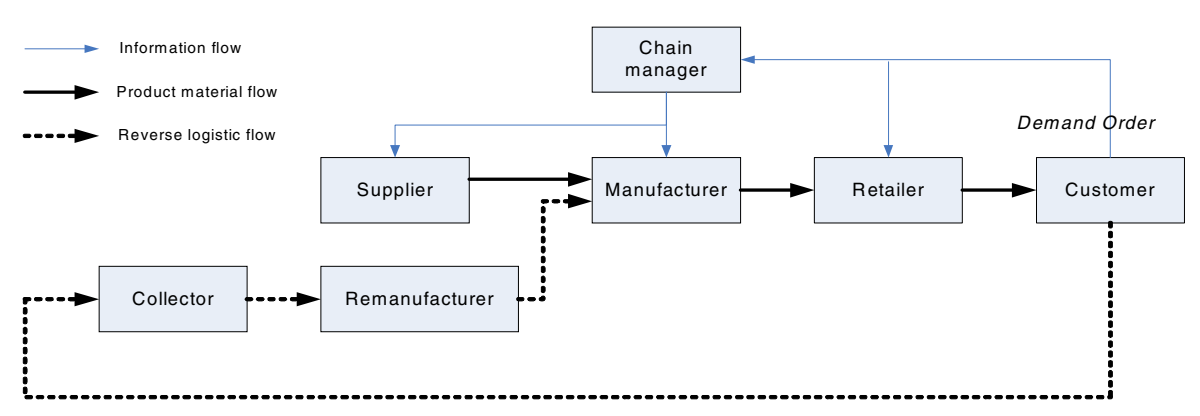

Fig. 1. Configuration the proposed reverse supply chain model

Meanwhile, Collector and Remanufacturer are members that form venous flows (reverse logistic flows) in a chain. The Collector reclaims used products from Customer, when he/she disposes the used product. And, it detaches reusable materials from the disposed product, and sends them to Remanufacturer. Remanufacturer produces remanufactured products by using materials from Collector. It provides the regenerated objects to Manufacturer, such as spare-parts.

\subsection{Reverse Logistics Models}

These models are based on an analogy between arterial-venous blood flows in a human body and material-flow in a supply chain. Solid lines are production generation flow (arterial-flow), meanwhile, dashed lines are reverse logistics flow (venous-flow) in Figure.2 and 3. Arterial-flows and venous-flow should be synchronized with each other. The system synchronizes venous flows with arterial flows.

The flow from Customer to Remanufacturer by way of Collector is a reverse logistics flow. Customer sends "used-products" to Collector, when Customer disposes them. The role of Collector is to distinguish reusable materials from the disposed products, and stores them. How much volume the Collector gathers reusable material from disposed materials depends on "Collection Rate". This is a probability variable that the Collector gathers reusable materials from the disposed material by Customers.

We defined two types of this reverse logistics flow: PUSH-type and PULL-type. The PUSH-type is that Collector and Remanufacturer sends reverse products to Manufacturer in an orderly manner. In PUSH-type, remanufactured products are sequentially pushed into Manufacturer, synchronizing with occurrence of reverse. Remanufactured product would be kept as material inventory in Manufacturer. In PUSH-type, remanufactured products are sequentially pushed into Manufacturer, synchronizing with occurrence of reverse. Remanufactured product would be kept as material inventory in Manufacturer.

Meanwhile, the PULL-type is that Collector and Remanufacturer work according as PULL signals from their downs-streams. In PULL-type, reverse products are stocked at Collector. These products stay at there, during no PULL signal from Remanufacturer. And, Remanufacturer does not work until it receives PULL signal. 
In Fig. 3, Collector works as "Stock-driven" mode. Collector continuously observes stock volume at Remanufacturer. It starts to produce products when the stock volume is smaller than the stock-replenishment level, and continues to work until the stock volume is equal to or greater than the stock-volume level. This works according to the following operational sequences:

1. Collector periodically observes stock volume data at Remanufacturer.

2. Collector starts producing while stock volume at Remanufacturer goes down below the stock-replenishment level.

3. Collector stops producing when the stock volume reaches the stock-volume level.

This logic is also applicable to the case of between Remanufacturer and Manufacturer.

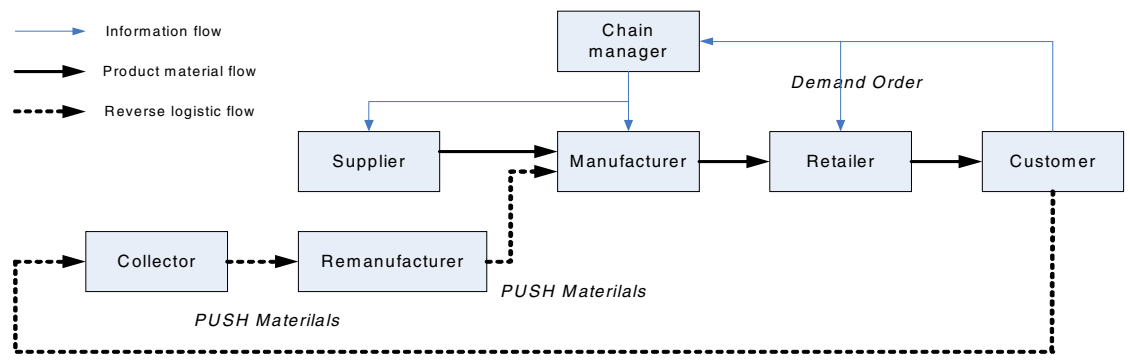

Fig. 2. PUSH-type reverse logistics model

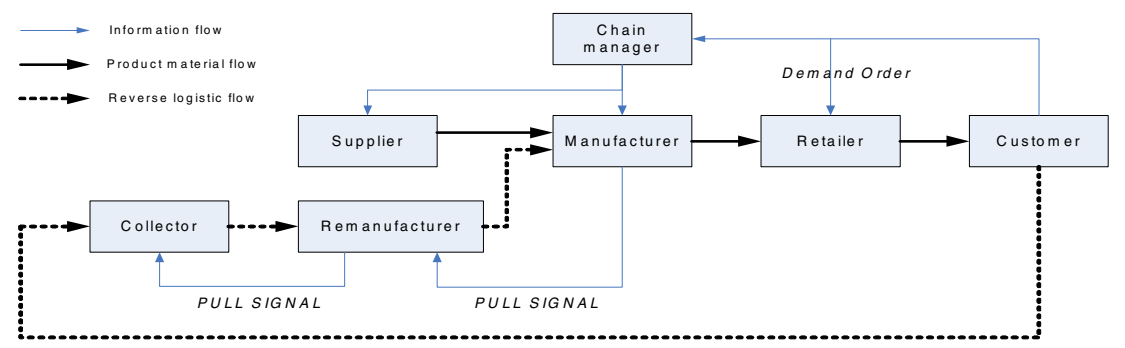

Fig. 3. PULL-type reverse logistics model

\section{Simulation Analysis}

The variable of Customer's order volume is obedient to a uniform distribution between 6 lots to 10 lots $(\mathrm{U}(6,10))$. And, the order interval of Customer is 5 days. Two levels of "Collection Rate" are defined. This is a probability variable that the Collector gathers reusable materials from the disposed material by Customers. These are 0.6 as high-level reverse and 0.2 as low-level reverse. Simulation duration is set on 100 days.

Table. 1 represents the differences between PUSH-type reverse and PULL-type reverse. The PULL system indicates higher utilization of Collector than the PUSH system. In PUSH system, the Collector works only when the materials arrive from it Upstream (Customer). Meanwhile, in PULL system, Collector works to replenish inventories at the downstream (Remanufacturer). This mechanism, accordingly, makes higher resource utilization, when the Collection Rate is at low level. 
Table 1. Simulation results (Utilizations of each supply chain member)

\begin{tabular}{|c|c|c|c|c|}
\hline Model & $\begin{array}{l}\text { Collection } \\
\text { Rate }\end{array}$ & $\begin{array}{l}\text { Utilization@ } \\
\text { Manufacturer }\end{array}$ & $\begin{array}{l}\text { Utilization@ } \\
\text { Collector }\end{array}$ & $\begin{array}{c}\text { Utilization@ } \\
\text { Re-manufacturer }\end{array}$ \\
\hline push & 0.6 & 0.92 & 0.32 & 0.30 \\
\hline push & 0.2 & 0.92 & 0.12 & 0.10 \\
\hline pull & 0.6 & 0.91 & 0.36 & 0.21 \\
\hline pull & 0.2 & 0.90 & 0.24 & 0.15 \\
\hline
\end{tabular}

Figure. 4,5,6, and 7 represent material inventories transitions at each supplier in individual simulation run. The material inventory volume at Manufacturer increases as time goes on in PUSH system (Fig.4, Fig.6). Meanwhile, the inventories at both Collector and Remanufacturer do not fluctuate so much. PUSH system processes the collected reusable materials in sequence to produce the regenerated parts, as far as its supply continues. The input material inventory in Manufacture, accordingly, keeps on increasing.

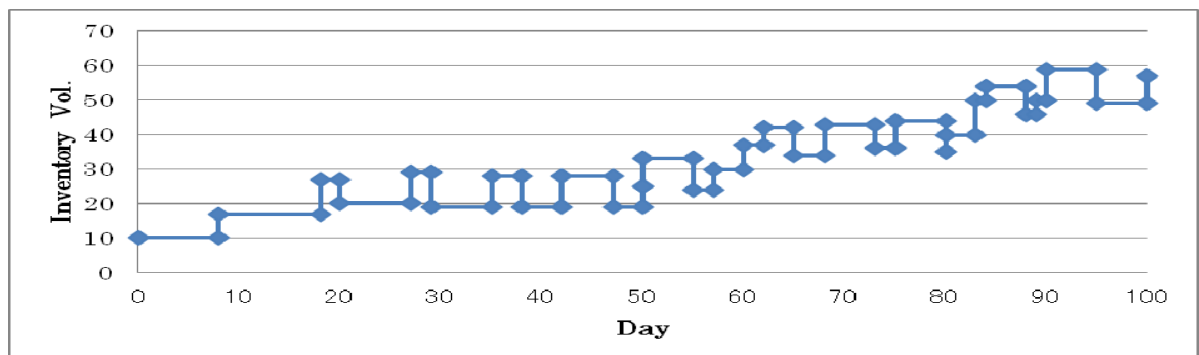

(a) Manufacturer

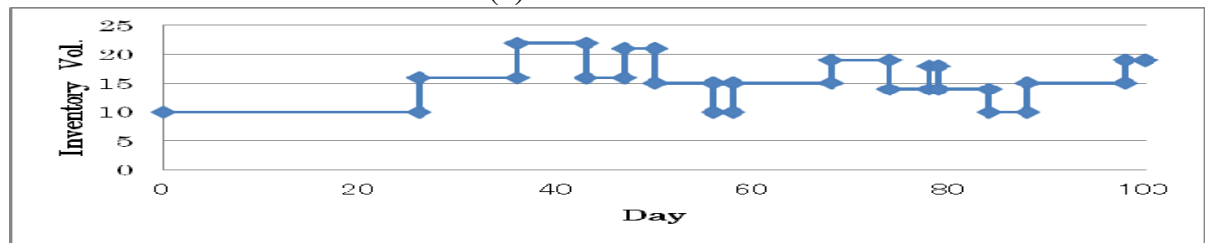

(b) Collector

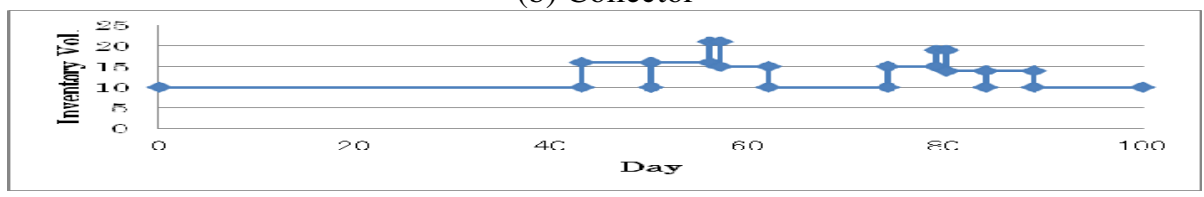

(c) Remanufacturer

Fig. 4. Material inventories transition at each supplier (PUSH model, Collection Rate=0.6)

In PULL system, material inventory volume at Manufacture keeps almost constant. Meanwhile, the volume of inventories at Remanufacturer demonstrates an upward trend, and materials at Collector are consumed. In PULL system, the material consumption at Collector synchronizes with material inventory volume at Remanufacturer, and 


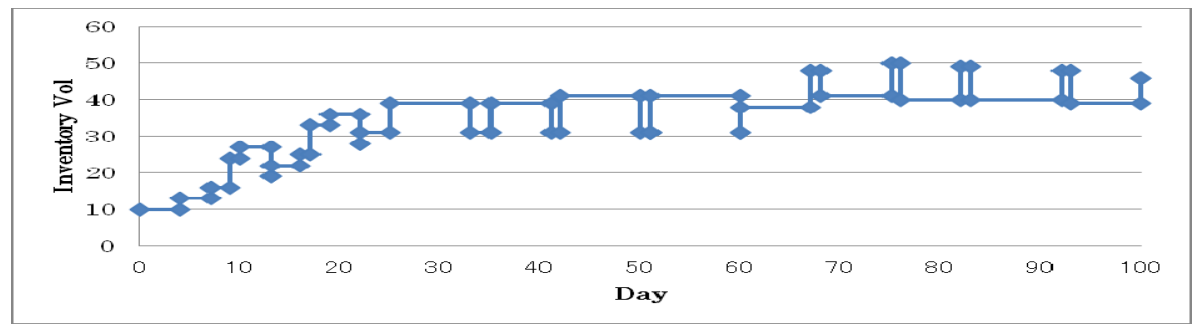

(a) Manufacturer

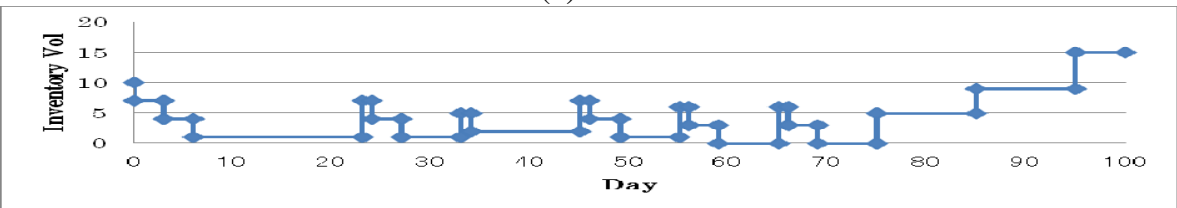

(b) Collector

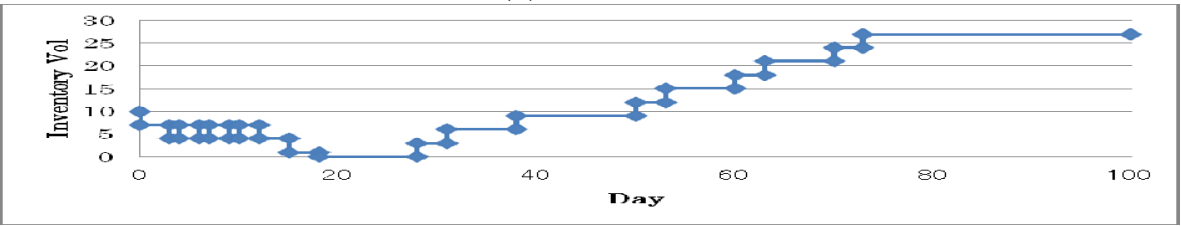

(c) Remanufacturer

Fig. 5. Material inventories transition at each supplier (PULL model, Collection Rate=0.6)

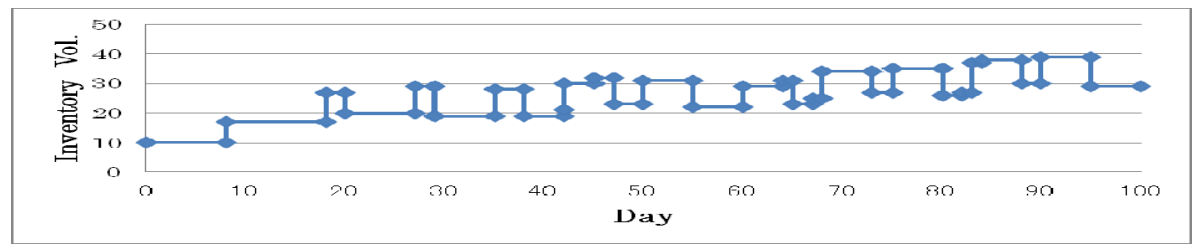

(a) Manufacturer

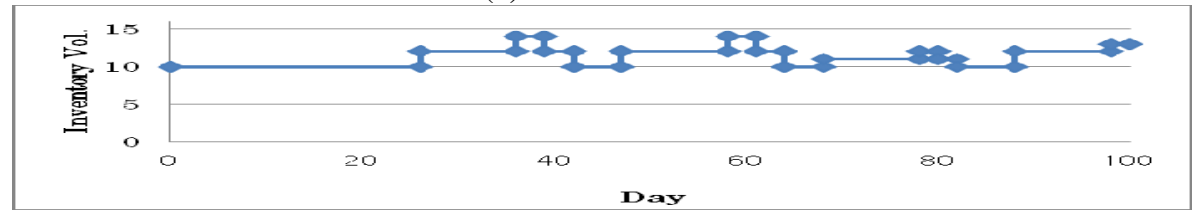

(b) Collector

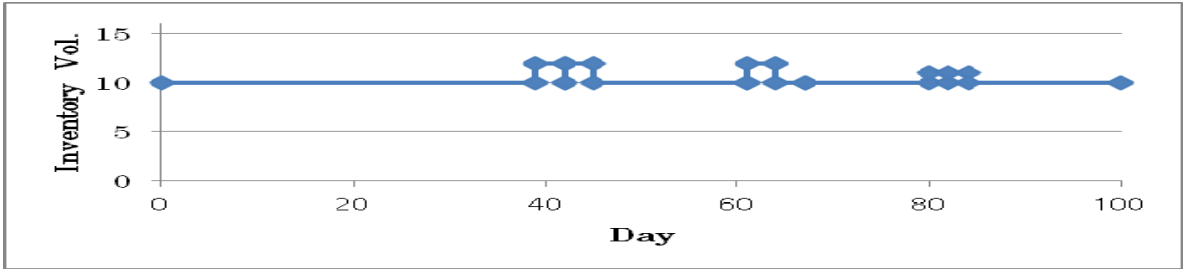

(c) Remanufacturer

Fig. 6. Material inventories transition at each supplier (PUSH model, Collection Rate=0.2) 


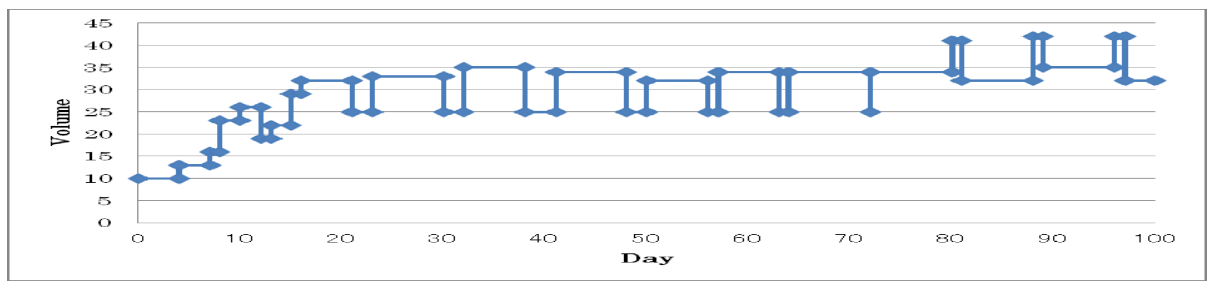

(a) Manufacturer

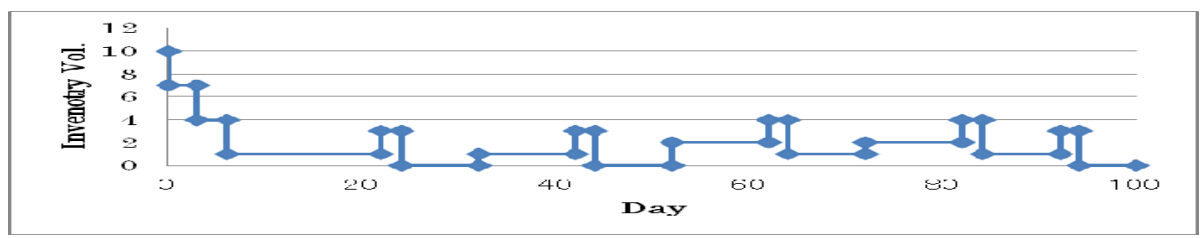

(b) Collector

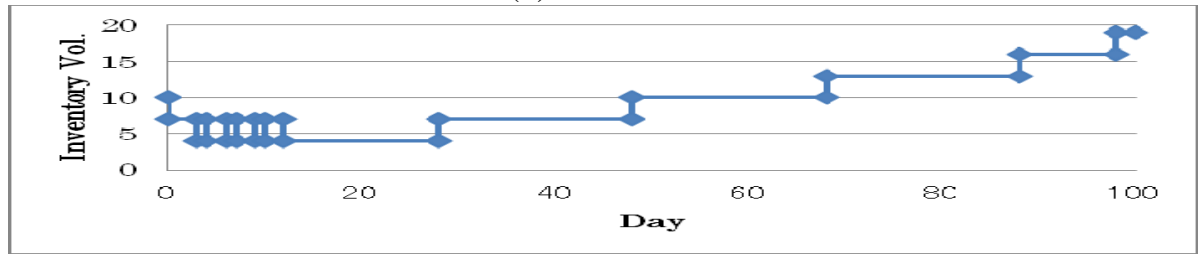

(c) Remanufacturer

Fig. 7. Material inventories transition at each supplier (PULL model, Collection Rate=0.2)

the material consumption at Remanufacturer synchronizes with material inventory volume at Manufacturer. When the Manufacturer possesses sufficient volume of input material, Remanufacturer does not need to provide Manufacturer with materials any more. (Fig.5, Fig.7)

\section{Conclusion}

In both PUSH system and PULL system, all of the reusable materials generated at Customer (market) are transferred to Collector. In PUSH system, the gathered materials in Collector are sent to Remanufacturer, which is a re-production process. After this regeneration process, materials accumulate on Manufacturer as its input materials. Meanwhile, in PULL system, the reusable materials staying at Collector would be transferred to Remanufacturer, only when the withdrawal signals from its downstream has been occurred. Therefore, reusable materials stocked in Collector demonstrates an upward trend. This reason suppresses increase of the materials in both Remanufacturer and Manufacturer.

The next stage of this simulation analysis will need to consider processes cost factors at both Collector and Remanufacturer. When the regeneration process at both Collector and Remanufacturer is expensive, the PULL system is the better choice. This is because the PULL system avoids overproductions. 


\section{References}

1. Gupta, S., Omkar, D.: Palsule-Desai: Sustainable supply chain management: Review and research opportunities. IIMB Management Review 23, 234-245 (2011)

2. Chouinarda, M., D’Amours, S., Aït-Kadia, D.: Integration of reverse logistics activities within a supply chain information system. Computers in Industry 56(1), 105-124 (2005)

3. Chung, C., Wee, H.: Green-component life-cycle value on design and reverse manufacturing in semi-closed supply chain. Int. J. Production Economics 113, 528-545 (2008)

4. de la Fuente, M.V., Rosa, L., Cardós, M.: Integrating Forward and Reverse Supply Chains: Application to a metal-mechanic company. Int. J. Production Economics 111, 782-792 (2008)

5. Emiliani, M.L.: Sourcing in the global aerospace supply chain using online reverse auctions. Industrial Marketing Management 33, 65-72 (2004)

6. Gou, Q., Liang, L., Huang, Z., Xu, C.: A joint inventory model for an open-loop reverse supply chain. Int. J. Production Economics 116, 28-42 (2008)

7. Minner, S.: Strategic safety stocks in reverse logistics supply chains. Int. J. Production Economics 71, 417-428 (2001)

8. Nagurney, A., Toyasaki, F.: Reverse supply chain management and electronic waste recycling: a multitiered network equilibrium framework for e-cycling. Transportation Research Part E 41, 1-28 (2005)

9. Chan, F.T.S., Zhang, T.: The impact of Collaborative Transportation Management on supply chain performance: A simulation approach. Expert Systems with Applications 38, 2319-2329 (2011)

10. Chatfield, D.C., Harrison, T.P., Hayya, J.C.: SISCO: An object-oriented supply chain simulation system. Decision Support Systems 42, 422-434 (2006)

11. Labarthe, O., Espinasse, B., Ferrarini, A., Montreuil, B.: Toward a methodological framework for agent-based modelling and simulation of supply chains in a mass customization context. Simulation Modelling Practice and Theory 15(2), 113-136 (2007)

12. Umeda, S., Lee, Y.T.: Integrated Supply Chain Simulation - A Design Specification for a Generic Supply Chain Simulation, NISTIR 7146, National Institute of Standards and Technology, US Dept. of Commerce (2004) 